\title{
Modelling and Analysis of Electromechanical Stress in Transformers Caused by Short-Circuits
}

\author{
Rosentino Jr. A. J. P. ${ }^{1}$, Saraiva E. ${ }^{1}$, Delaiba A. C. ${ }^{1}$, Guimarães R. ${ }^{1}$, Lynce M. ${ }^{1}$, De Oliveira J. C. ${ }^{1}$, Fernandes \\ Jr. D. ${ }^{2}$, Neves W. ${ }^{2}$ \\ ${ }^{1}$ Faculty of Electrical Engineering \\ Federal University of Uberlândia \\ 2121, Av. João Naves de Ávila, Department 3N, Santa Mônica, Uberlândia/MG - Brazil \\ Phone/Fax number:+55 34 32394763, e-mail: arnaldoufu@gmail.com, elise.saraiva@yahoo.com.br, \\ delaiba@ufu.br, lynce@ufu.br, jcoliveira@ufu.br, ronaldoguimaraes@yahoo.com.br \\ ${ }^{2}$ Center of Electrical Engineering and Computer Science, Electrical Engineering Department \\ Federal University of Campina Grande \\ 882, Av. Aprígio Veloso, DEE/CEEI/UFCG, Electrical Systems Group, 58429-140 - Campina Grande/PB - Brazil \\ Phone/Fax number:+55 83 33101267, e-mail: damasio@dee.ufcg.edu.br, waneves@dee.ufcg.edu.br
}

\begin{abstract}
A common reason for internal faults in transformers windings is the weakness insulation caused by vibration / deformation related to electromechanical forces produced by high short circuit currents. This phenomenon significantly reduces the transformer life expectancy and may even lead to its instantaneous or timing destruction. Focusing this subject this paper is aimed at presenting the performance of a time domain model inserted in a finite element program i.e. the 3D software package and the investigation of the relationship between high current levels occurring at transformer windings and the internal mechanical stresses. To highlight the overall model and the software performance, a laboratory $15 \mathrm{kVA}$ transformer is utilized to show the programme facilities and potentially. The transformer has been built with concentric double-layer windings and ferromagnetic core with three columns and this equipment has been submitted to a balanced three-phase short- circuit. In addition, the computational simulations were carried out using distinct geometries to the windings i.e. with and without deformation.
\end{abstract}

\section{Key words}

Mechanical transformer stresses, radial forces, axial forces, windings deformations, finite element simulation.

\section{Introduction}

Power transformers are essential devices and represent a significant part of the overall electrical system cost. When these devices are damaged or fail their repair or even the replacement demand very high financial costs. The reason for that is the high commercial cost of this equipment as well as the energy loss transference during a period of time [1]. The failures of these devices are mainly due to the weakness insulation caused by the electrochemical process involving the cooling liquid (oil), the vibrations produced by the electromechanical forces during normal operation, i.e. in steady state, and also by windings deformations caused by high short circuit currents. An analytical methodology which includes studies related to electromechanical transformer stress caused by short-circuit is presented in references [2] and [3].
Focusing the above subject this paper aims to present the results of an investigation in the field of electromechanical stresses. The idea consists in using a finite element model for the transformer so as to calculate the corresponding radial and axial forces. The software selected is the flux 3D software package which is a very well known product offered by CEDRAT - France. Throughout the insertion of the transformer equations in the mentioned program it becomes possible to perform investigation studies in relation to the effect of shortcircuit conditions on the transformer internal mechanical forces. To illustrate the computational facilities, investigations about the relationship between three-phase short circuits and their effects on a given transformer are then carried out using a laboratory $15 \mathrm{kVA}$ transformer data. This device is made of traditional ferromagnetic core with three columns and two concentric windings double layer. Two different situations concerning the winding conditions, with and without internal deformation have been taken into account. The computational results are, at the end, compared to expected values derived from analytical expressions traditionally used for such calculations, as well as from experimental tests.

\section{Electromechanical Failures In Transformers}

Under normal operation, the electromechanical forces and the leakage flux in the transformer are relatively small. Therefore, the mechanical structures support the efforts with no difficulty. However, under short-circuit condition, if the coils are not adequately built with appropriate mechanical structures, the leakage flux associated with high currents reach relatively high values. It could cause a partial or even a complete mechanical destruction of the transformer built in structure [2].

\section{A. Radial forces}

The radial forces are produced by the axial component of leakage flux and it results in different effects in the outer 
and the inner windings of the transformers. For core type transformers, the tendency of the mechanical stresses is to compress (compression stress) the inner winding and expand (tensile stress) the outer winding [2].

The occurrence of radial deformation in the inner winding is more common than in the outer winding [2] and it may occur due to two distinct ways. One is the forced buckling, which occurs when the inner winding is supported by spacers located in the axial direction to the conductors [4]. This happens when the stress value exceeds the material elastic limit. The other strain is known by free buckling. In this case the conductor is deformed in one or more radial points of the coil winding. These effects are illustrated in Fig.1 [4, 5, 6].

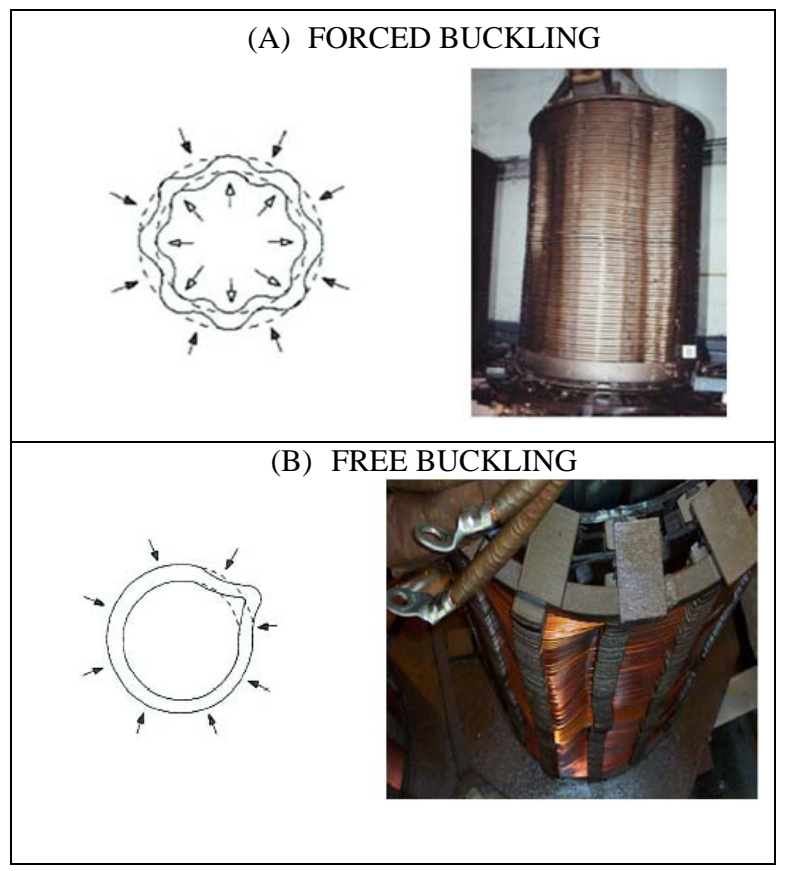

Fig. 1. Typical effects of electromechanical stress on the transformer windings caused by radial forces. (A) Forced Buckling), (B) Free Bucking.

\section{B. Axial forces}

The axial forces are produced by the radial component of the leakage flux and it is responsible by the compressing of the windings. Under these circumstances, the windings conductors can bend between the insulating spacers located radially or leaning to each other. The occurrence of this latter phenomenon is typical for the disc type windings. This is the arrangement generally used in large transformers. These effects are illustrated in Fig.2 [1, 6, 7].

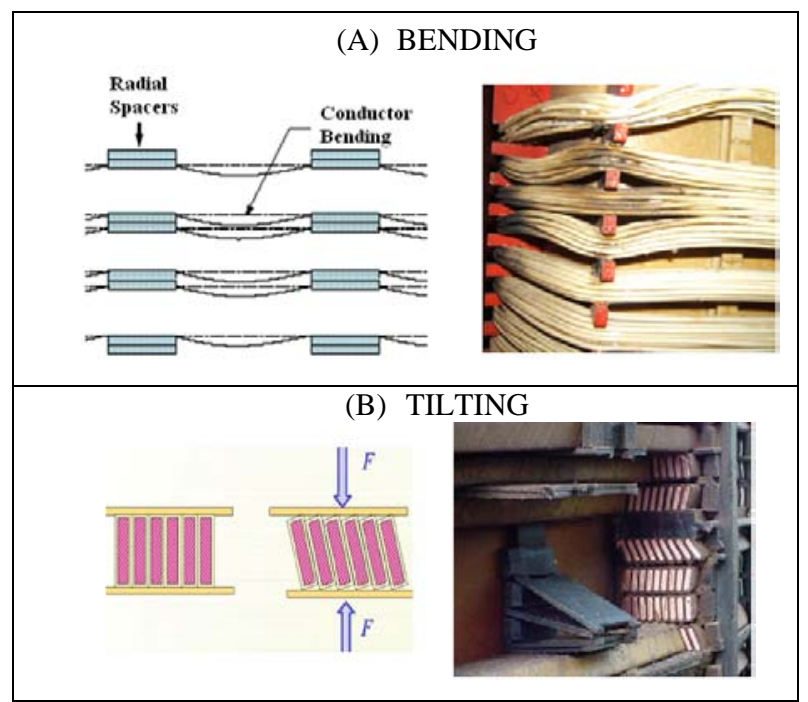

Fig. 2. Typical effects of electromechanical stress on the transformer windings caused by axial forces. (A) Bending, (B) Tilting.

It must be pointed out that the axial displacement of the windings and the use of the transformer tap facilities contribute considerably to the increase of the axial forces in the coils.

\section{Computational Analysis}

Computer simulations then were performed using the software package FLUX in its $3 \mathrm{D}$ version. This software has pioneered the development of formulations based on finite element method (FEM). The FLUX basic modules include the preprocessing (geometry, definition of physical properties, and meshes), the processing (problem solving) and post processing to results analysis.

\section{A. Transformer constructive characteristics}

Figure 3 shows some physical and geometrical characteristics of the transformer modeled. The equipment is three-phase, star connection, $15 \mathrm{kVA}$, with two double-layer windings per phase, each with a rated voltage of $127 \mathrm{~V}$. Each winding has two layers with 33 turns which leads to a total of 66 turns per coil [8]. 


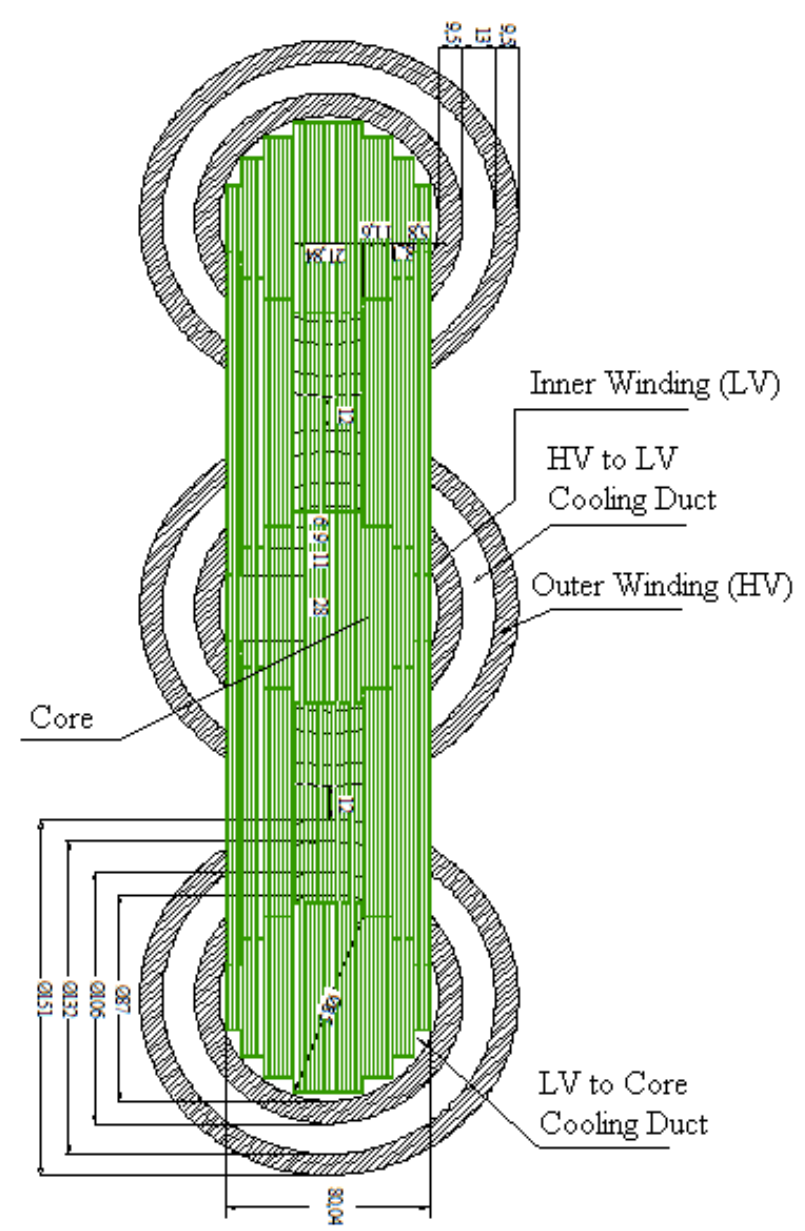

Fig. 3. Geometrical and physical characteristics of the transformer analysed (dimensions in $\mathrm{mm}$ ).

Based on the geometrical and electrical characteristics of the transformer (Figure 3), two conditions were simulated. The first considers no deformation for the windings and the second takes into account such situation. Using these two cases the balanced three-phase short circuit has been applied.

\section{B. Case 1: Transformer analysis involving windings without deformation}

Figure 4 shows the model implemented in software. It is possible no notice that the detailed geometric and physical information have been fully considered. It can be noted that only a quarter of the transformer was considered. This technique is widely used in applications based on finite element method because it reduces the processing time of the simulation. The software automatically completes the geometry, considering it is symmetrical.

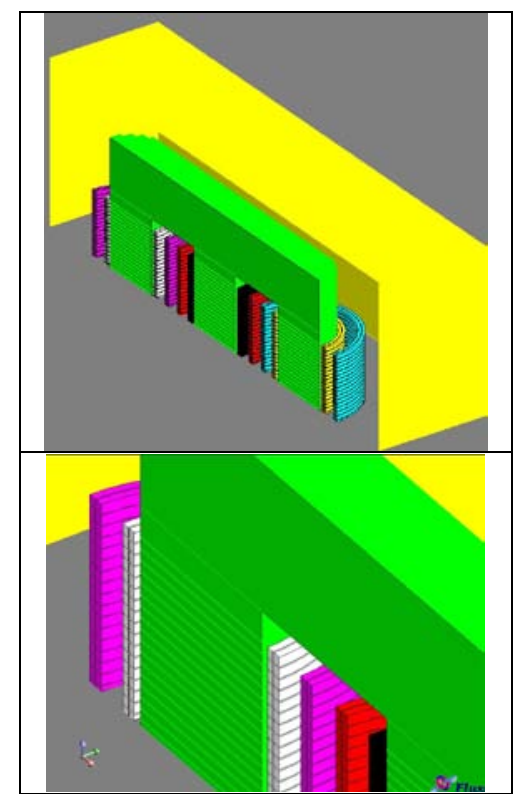

Fig. 4. The transformer implemented in the FLUX3D.

Figure 5 shows the leakage flux distribution in the transformer at the occurrence of the three-phase shortcircuit. It can be seen that the highest intensity for the magnetic induction is found between the windings (yellow intensity). This is the place where the greatest forces and electromechanical stresses are detected.

Figure 6 identifies the electromechanical stress values in the inner and the outer windings. It can be observed that the highest intensities, in accordance with the colored distribution in Figure 6, occur for both the inner and the outer winding layers near the region of greatest magnetic induction.

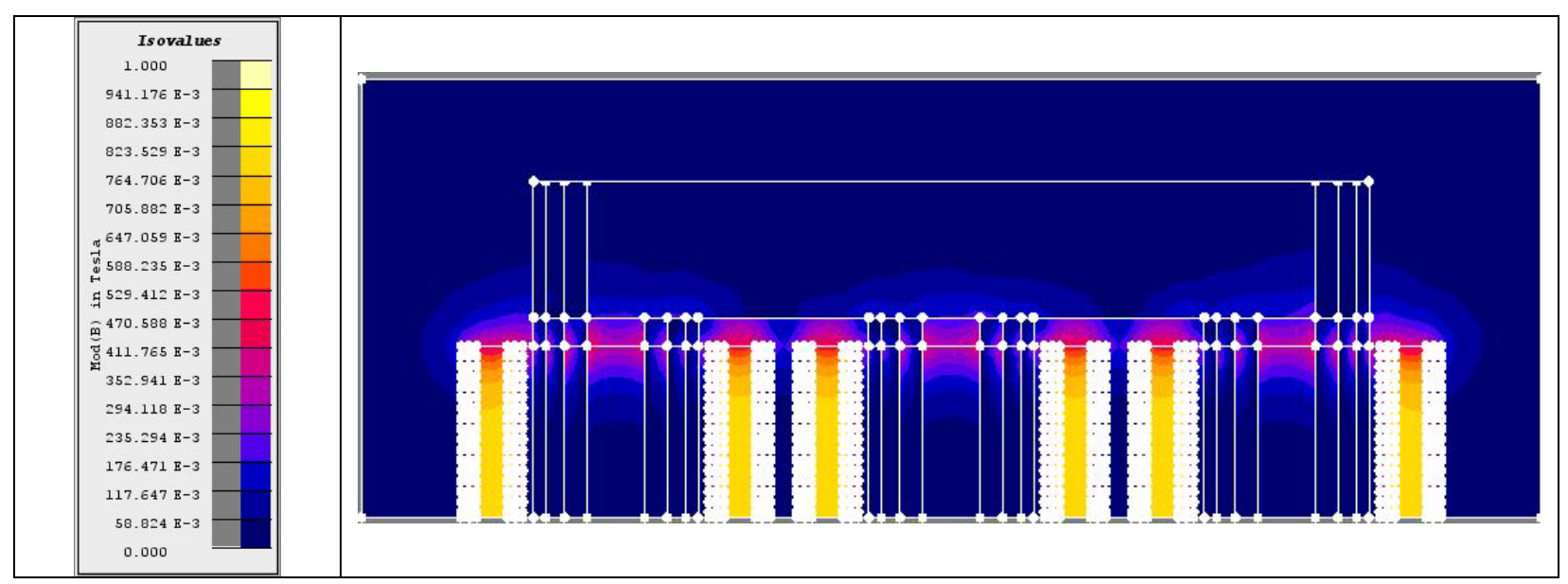

Fig. 5. Leakage flux distribution in the transformer under three-phase short-circuit condition (windings without deformations). 


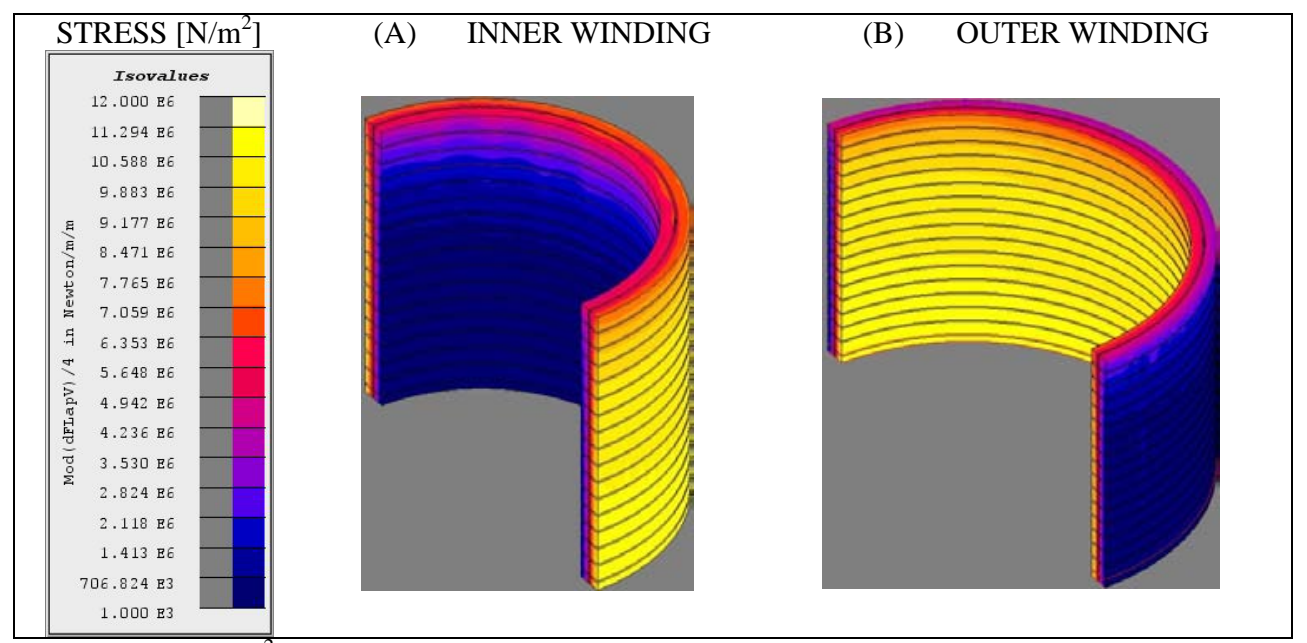

Fig. 6. Electromechanical Stress $\left(\mathrm{N} / \mathrm{m}^{2}\right)$ in the inner (A) and outer winding (B).

To have an alternative way to calculate and to estimate the forces obtained from the FLUX 3D, comparisons were made between the magnitudes derived from simulations with laboratory measurements and analytical methodologies. Two scenarios were taken as reference: the measurement results obtained during the open circuit test and, complementary, the analytical calculations with short-circuit condition.

From the open circuit test with star connection and insulated neutral, the data obtained is summarized in Table I.

Table I. - Magnetizing current peak values and core loss obtained from measurements and simulations - open circuit conditions.

\begin{tabular}{|l|c|c|}
\hline VARIABLE & MEASUREMENT & SIMULATION \\
\hline $\begin{array}{l}\text { Line A } \\
\text { current }\end{array}$ & $2.3[\mathrm{~A}]$ & $2.2[\mathrm{~A}]$ \\
\hline $\begin{array}{l}\text { Line B } \\
\text { Current }\end{array}$ & $1.5[\mathrm{~A}]$ & $1.4[\mathrm{~A}]$ \\
\hline $\begin{array}{l}\text { Line C } \\
\text { Current }\end{array}$ & $2.3[\mathrm{~A}]$ & $2.2[\mathrm{~A}]$ \\
\hline $\begin{array}{l}\text { Core } \\
\text { losses }\end{array}$ & $87.6[\mathrm{~W}]$ & $93.0[\mathrm{~W}]$ \\
\hline
\end{tabular}

Under short circuit conditions, the currents and leakage inductances are those given in Table II.

Table II. - Values of the simulated and calculated short-circuit current and leakage inductance.

\begin{tabular}{|l|c|c|c|}
\hline VARIABLE & $\begin{array}{c}\text { ANALYTICAL } \\
\text { METHOD }\end{array}$ & SIMULATION & $\begin{array}{c}\text { ERROR } \\
{[\%]}\end{array}$ \\
\hline $\begin{array}{l}\text { Three-phase } \\
\text { short-circuit } \\
\text { current }\end{array}$ & $1755[\mathrm{~A}]$ & $1646[\mathrm{~A}]$ & 6.6 \\
\hline $\begin{array}{l}\text { Leakage } \\
\text { inductance }\end{array}$ & $234[\mu \mathrm{H}]$ & $237[\mu \mathrm{H}]$ & 1.27 \\
\hline
\end{tabular}

Table III is related to the analytical and computational results of the electromechanical forces and stresses when the short circuit condition occurs. It can be seen that the largest differences occur in the values of the radial forces.
This fact can be explained by the simplifications adopted and limitations of the analytical methodology [2, 3].

Based on the results, the laboratory and the analytical approaches show a good agreement with the values derived from simulations.

Table III. - Forces and stresses resulting from the short circuit condition.

\begin{tabular}{|c|c|c|c|}
\hline VARIABLE & $\begin{array}{l}\text { ANALYTICAL } \\
\text { METHOD }\end{array}$ & SIMULATION & $\begin{array}{c}\text { ERROR } \\
{[\%]}\end{array}$ \\
\hline $\begin{array}{l}\text { Radial } \\
\text { force } \\
\text { inner } \\
\text { winding }\end{array}$ & $15303[\mathrm{~N}]$ & $18418[\mathrm{~N}]$ & 20.35 \\
\hline $\begin{array}{l}\text { Radial } \\
\text { force } \\
\text { outer } \\
\text { winding }\end{array}$ & 22439 [N] & $24821[\mathrm{~N}]$ & 10.6 \\
\hline $\begin{array}{l}\text { Axial force } \\
\text { ends of the } \\
\text { inner } \\
\text { winding }\end{array}$ & $367.5[\mathrm{~N}]$ & $319[\mathrm{~N}]$ & 13.2 \\
\hline $\begin{array}{l}\text { Axial force } \\
\text { ends of the } \\
\text { outer } \\
\text { winding }\end{array}$ & $367.5[\mathrm{~N}]$ & $306[\mathrm{~N}]$ & 16.7 \\
\hline $\begin{array}{l}\text { Radial } \\
\text { stress } \\
\text { Inner } \\
\text { winding } \\
\end{array}$ & $\begin{array}{c}2.34 \times 10^{6} \\
{\left[\mathrm{~N} / \mathrm{m}^{2}\right]}\end{array}$ & $\begin{array}{c}2.8 \times 10^{6} \\
{\left[\mathrm{~N} / \mathrm{m}^{2}\right]}\end{array}$ & 19.67 \\
\hline $\begin{array}{l}\text { Radial } \\
\text { stress } \\
\text { outer } \\
\text { winding }\end{array}$ & $\begin{array}{c}3.44 \times 10^{6} \\
{\left[\mathrm{~N} / \mathrm{m}^{2}\right]}\end{array}$ & $\begin{array}{c}3.8 \times 10^{6} \\
{\left[\mathrm{~N} / \mathrm{m}^{2}\right]}\end{array}$ & 9.47 \\
\hline
\end{tabular}

B. Case 2: Transformer analysis involving the inner winding of the middle limb with deformation

In this case, the inner winding of the middle limb is modeled with a given deformation as illustrated by Figure 7. This strain is presented in Figure 1, which is known by free buckling. Similarly to case 1, a threephase short-circuit has been applied to the transformer. 


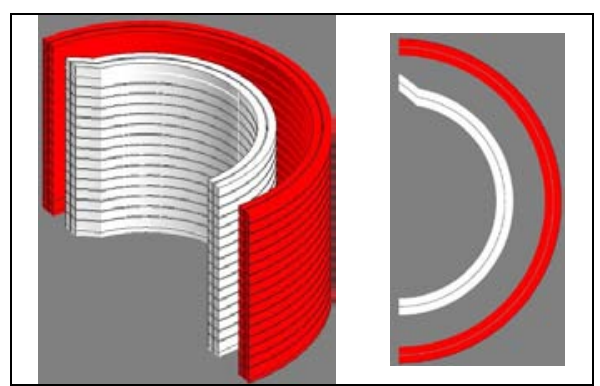

Figures 8 and 9, respectively, show the leakage flux distribution and the electromechanical stress values in the inner and the outer windings in the transformer for this situation. Once again, the highest magnetic induction intensities, as shown by the colored distribution, are located between the windings, as well as the highest stresses occur for both the inner and the outer winding layers near the region of greatest magnetic induction.

Fig. 7. Model of the transformer involving the inner winding of the middle limb with deformation.

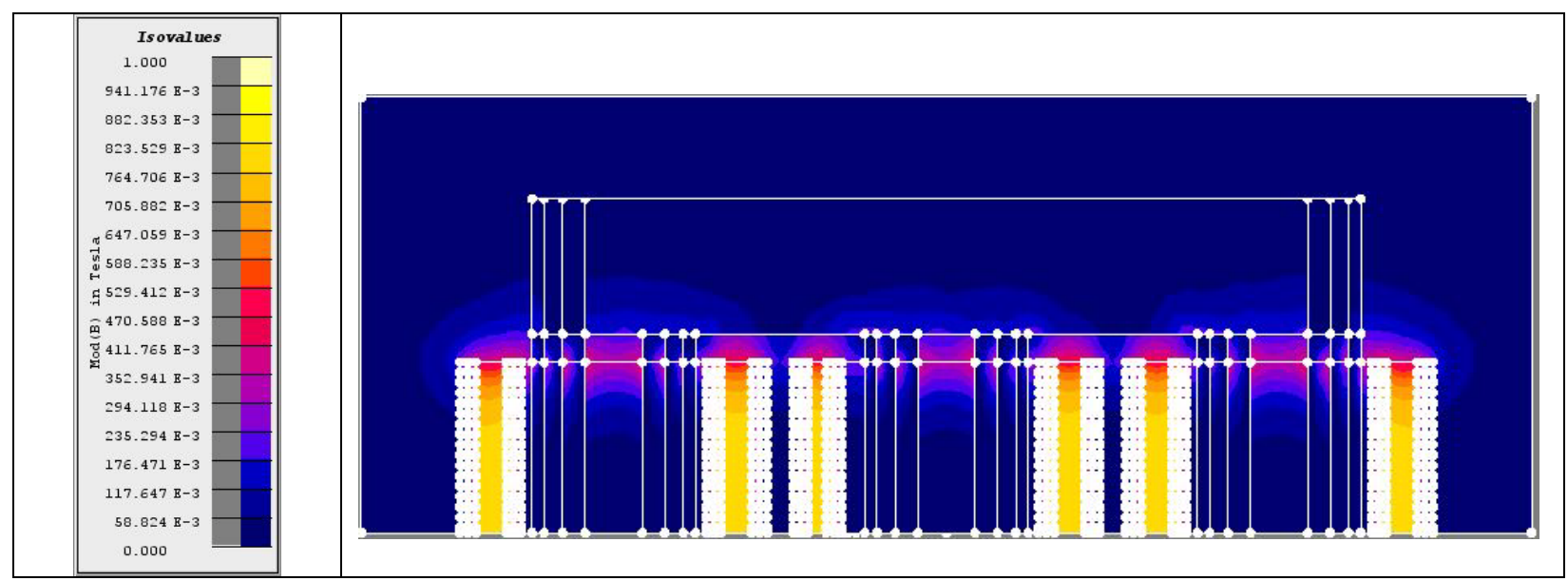

Fig. 8. Leakage flux distribution in the transformer under three-phase short-circuit condition (inner winding of the middle limb with deformation).

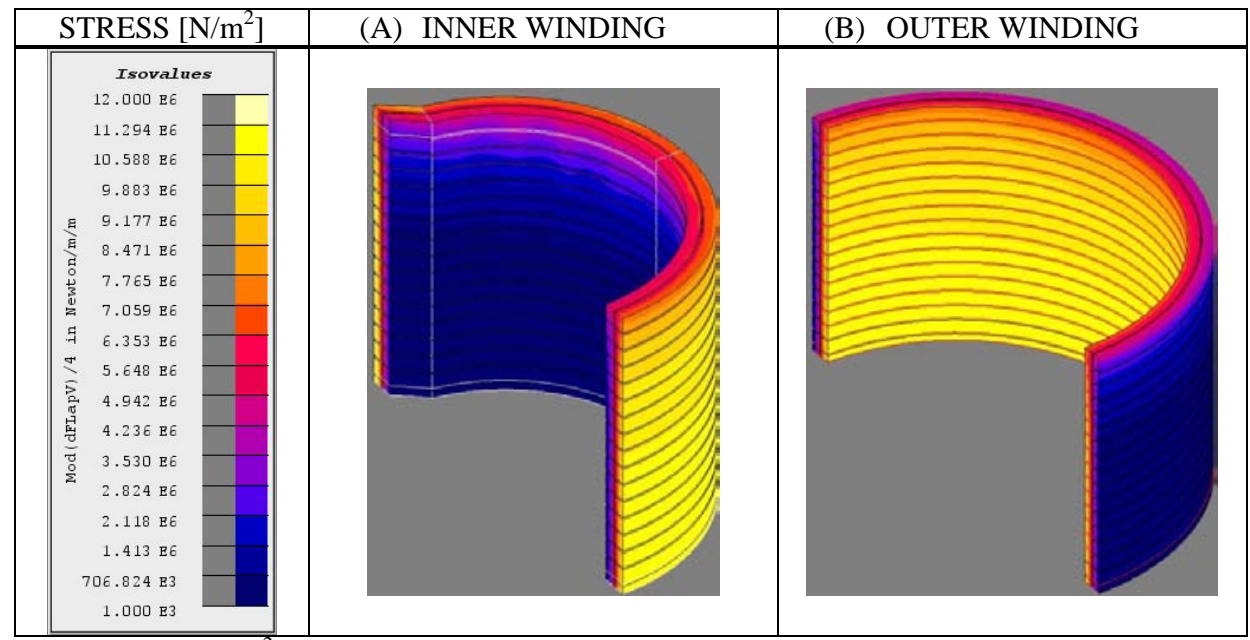

Fig. 9. Electromechanical stresses $\left(\mathrm{N} / \mathrm{m}^{2}\right)$ in the inner - with deformation (A) and outer winding (B). 
Table IV shows the changes of the electrical, magnetic and mechanical transformer variables that are found under the new condition here imposed, i.e. with deformation of the inner winding.

Table IV. - Variations of the electrical, magnetic and mechanical variables at the inner winding with deformation.

\begin{tabular}{|l|c|}
\hline \multicolumn{1}{|c|}{ PARAMETER } & $\begin{array}{c}\text { PERCENTUAL } \\
\text { DIFFERENCE } \\
\text { COMPARED TO THE } \\
\text { WINDING } \\
\text { WITHOUT DEFORMATION } \\
\text { [\%] }\end{array}$ \\
\hline $\begin{array}{l}\text { Three-phase } \\
\text { short-circuit } \\
\text { current }\end{array}$ & +0.5 \\
\hline $\begin{array}{l}\text { Leakage } \\
\text { inductance }\end{array}$ & -1.0 \\
\hline $\begin{array}{l}\text { Radial force } \\
\text { inner winding }\end{array}$ & +7.1 \\
\hline $\begin{array}{l}\text { Radial force } \\
\text { outer winding }\end{array}$ & +1.09 \\
\hline $\begin{array}{l}\text { Axial force } \\
\text { ends of the } \\
\text { inner winding }\end{array}$ & -0.32 \\
\hline $\begin{array}{l}\text { Axial force } \\
\text { ends of the } \\
\text { outer winding }\end{array}$ & +1.08 \\
\hline $\begin{array}{l}\text { Radial stress } \\
\text { inner winding }\end{array}$ & +2.86 \\
\hline $\begin{array}{l}\text { Radial stress } \\
\text { outer winding }\end{array}$ & +6.6 \\
\hline
\end{tabular}

It above results makes clear that the deformation in the winding has caused variations of the electrical, magnetic and electromechanical values. It can be seen that the variation of the radial forces and stresses in the inner winding were higher than that in the outer winding. This can be attributed to the fact that the deformation was applied in the inner winding and therefore the leakage flux distribution in this winding was more varied. In addition, at the end of the windings, it can be noted that the axial forces keep practically constants. This fact can be explained, particularly for this deformation, by the leakage flux distribution in the radial direction (causing the axial force) varies less and is more irregular than that in the axial direction (causing the radial force). Finally, the small decrease of the leakage inductance can be explained by the reduction of the HV to LV cooling duct, due to the deformation applied.

\section{Conclusion}

This paper presented the results of investigation on the relationship between electrical, magnetic and electromechanical effects in transformer, with symmetrical and asymmetrical windings physical conditions, at the occurrence of short-circuit currents, and their impact on the mechanical axial and radial forces. The simulations results using a finite element program and time domain representation for the transformer has shown that the deformations in the windings can increase the electromechanical stress in the windings, indicating the possibility of damaging them.

The deformations exemplified in this paper are usually derived from small deformations in the windings and they can represent a physical and real effect accumulated over the transformer operation along its working time. It has been verifies that the higher the deformation, the bigger the electromechanical forces between the windings. As the equipment becomes older the more fragile it will be. This will certainly have a strong effect on the risk of failure, even with low stress values that occurs during the life operation.

Currently, with the difficulties imposed by the standards it becomes uneconomical the outage of transformers and other components. This arises the importance of knowing the physical conditions of a given transformer so that it may not be the reason for supply interruption of blackouts.

\section{Acknowledgement}

This paper is a partial result of a Research and Development project titled: "Electromechanical stress in transformer caused by the high inrush and short-circuit currents", managed by the Hydroelectric Company of San Francisco - CHESF, with support from the Federal University of Uberlandia - UFU and the Federal University of Campina Grande - UFCG. Thus, the authors gratefully appreciate the Hydroelectric Company of San Francisco - CHESF for the financial support.

\section{References}

[1] AZEVEDO, A. C.. "Estresse Eletromecânico em Transformadores Causado por Curtos-Circuitos "Passantes" e Correntes de Energização". Tese (Doutorado) Universidade Federal de Uberlândia, Fevereiro 2007.

[2] WATERS, M.. "The Short-Circuit Strength of Power Transformers". 5. ed.: Macdonald and Co., London, 1966.

[3] ROSENTINO, A.; SARAIVA, E.; DELAIBA, A. C.; BRONZEADO, H. S.; OLIVEIRA, J. C.; CHAVES, M. L. R.. "Estresse Eletromecânico em Transformadores Causado por Curtos-Circuitos Trifásicos". The 8th Latin-American Congress on Electricity Generation and Transmission. CLAGTEE, Ubatuba, Outubro 2009.

[4] Working Group 12.19 CIGRE. "The Short Circuit Performance of Power Transformers”. Brochure 209, August 2002.

[5] BJERKAN, E.. "High Frequency Modeling of Power Transformers - Stresses and Diagnostics". Doctoral Thesis - Faculty of Information Technology, Mathematics and Electrical Engineering, Trondheim, May 2005.

[6] DOBLE. "The Life of a Transformer. Seminar and Industry Expo". Florida February 19-25, 2006.

[7] Working Group A2.26 CIGRE. "Mechanical-Condition Assessment of Transformer Windings Using Frequency Response Analysis (FRA)”. Brochure 342, April 2008.

[8] SARAIVA, E.; CHAVES, M. L. R.; CAMACHO, J. R.. "Modelagem de um Transformador de 15 kVA no FEMM, e Metodologia para Cálculo dos Entreferros”. VIII Conferência Internacional de Aplicações Industriais Induscon. Poço de Caldas, Agosto 2008. 